\title{
Toxicity Assessment of Phosphonium Based Ionic Liquids Towards Female Guppy Fish
}

\author{
${ }^{1}$ Mohanad El-Harbawi, ${ }^{2}$ Yasmin Syazwani Bt. Yusri and ${ }^{3}$ M. Ismail Hossain \\ ${ }^{1}$ Department of Chemical Engineering, Faculty of Engineering, King Saud University, Riyadh, 11421, Saudi Arabia \\ ${ }^{2}$ Faculty of Chemical Engineering, University Teknologi MARA, 40200 Shah Alam, Selangor, Malaysia \\ ${ }^{3}$ Department of Chemical Engineering, Faculty of Engineering, \\ University Teknologi PETRONAS, 31750, Tronoh, Perak, Malaysia
}

Received 2013-07-15; Revised 2013-07-22; Accepted 2014-01-20

\begin{abstract}
In this study, two phosphonium based ionic liquids (butyl triphenyl phosphonium chloride and hexyl triphenyl phosphonium bromide) have been synthesized using quarternisation process. The toxicities of these Ionic Liquids (ILs) are unknown and may be harmful to humans and the environment. Therefore, the toxicity assessment of these ILs was carried out according to the Organization for Economic Cooperation and Development (OECD) 203 guideline using female guppy fish (Poecilia reticulata). The median Lethal Concentrations $\left(\mathrm{LC}_{50}\right)$ have been estimated for butyl triphenyl phosphonium chloride and for hexyl triphenyl phosphonium bromide to be 73.35 and $61.36 \mathrm{mg} \mathrm{L}^{-1}$ respectively. Both $\mathrm{LC}_{50}$ obtained can be identified as slightly toxic ILs based on Acute Toxicity Rating Scale by Fish and Wildlife Service (FWS). The findings from this study can be used for better design of phosphonium-based ILs with consideration of their aquatic toxicities.
\end{abstract}

Keywords: Ionic Liquids, Fish, Toxicity, Lethal Concentration

\section{INTRODUCTION}

The world of Ionic Liquids (ILs) started by Walden (1914) who synthesized ethylammonium nitrate $\left[\mathrm{EtNH}_{3}\right]\left[\mathrm{NO}_{3}\right]$. Later, after several years, ILs began to gain more of the attention of scientists when first room temperature IL with a 1-alkyl-3-methylimidazolium cation was reported (Wilkes et al., 1982). ILs are composed of ions only and they are fluid below $100^{\circ} \mathrm{C}$ due to asymmetry of one of the ions. They are thermally stable with liquid range up to $300^{\circ} \mathrm{C}$ compared to $100^{\circ} \mathrm{C}$ for water and show very low vapour pressure, which makes them of great interest due to these properties. ILs typically consist of bulky organic cations, such as imidazolium, pyridinium, ammonium, phosphonium, paired with various anions, such as hexaflurophosphate $\left(\mathrm{PF}_{6}{ }^{-}\right)$, bromide $\left(\mathrm{Br}^{-}\right)$ (Pernak et al., 2005; Freire et al., 2006; Flieger, 2011; Peric et al., 2012). They are currently considered as a remarkable class of solvents due to their large liquidous range and non-volatile behaviour and can be used for a broad range of industrial applications. Research on this area is rapidly increasing due to their exciting applications and wide usages. The reason for the increasing interest is clearly due to the realization that these materials have a greater utility as solvents for reactions and material processing, media for extraction and working fluids for mechanical applications. Volatile Organic Compounds (VOCs) were previously used as solvents (such as, methanol, ethanol, benzene, toluene, ether) in industrial applications causing a major concern in the current chemical processing industry. Although intensive information and data regarding ILs' physical and thermodynamic properties have been reported and continuously published, only limited data with regard to the toxicity and ecotoxicity were reported (Bernot et al., 2005a; 2005b; Latala et al., 2005; Pretti et al., 2006; Madria et al., 2013). The toxic effects of many solvents combined with serious environmental issues, such as

Corresponding Author: Mohanad El-Harbawi, Department of Chemical Engineering, Faculty of Engineering, King Saud University, Riyadh, 11421, Saudi Arabia 
atmospheric emissions and contamination of aqueous effluents are making them harmful to use. Thus, many researchers have emphasized on the improvement of green engineering which represents research aimed at finding environmentally benign alternatives to harmful chemicals. Among the neoteric solvents applicable in green technologies, ILs have garnered increasing attention over the others due to their numerous applications in recent years. In general, the toxicity of chemicals can be measured using (a) mammalian acute toxicity test (b) bacteria acute toxicity test (c) fish acute toxicity test and (d) biological dissociation test (Ardali, 1990; Dube and Hosetti, 2010). The aquatic toxicity assessment is the study of the effects of the chemicals and other anthropogenic and natural materials and activities on aquatic organisms at various levels of organization and ecosystems. The effects can cause both positive and negative alteration from previously existing circumstances, but aquatic toxicology focuses primarily on the deviations that are considered to be adverse in nature and on recovery processes in biota that may occur when the exposure diminishes. Adverse effects at the organismal level include both the short-term (acute) and long-term (chronic) lethality (expressed as mortality or survival) and sub-lethal effects such as changes in behaviour, growth, development, reproduction, detoxification activities and tissue structure. Adverse effects at the sub-organismal level include induction or inhibition of enzymes and/or phenotypes, as well as changes in the number, relative abundance and physiological condition of species typically found in a given community type (Rand and Wells, 1995). There are several test species that are recommended by the OECD guidelines, which are rainbow trout (Oncorhynchus mykiss), fathead minnow (Pimephales promelas), bluegill (Lepomis macrochirus), zebrafish (Danio rerio), medaka (Oryzias latipes), guppy (Poecilia reticulata) and common carp (Cyprinus carpio). A number of acute toxicity studies have been performed using a variety of fish. For instance, McKim (1977) used Chinook salmon (Oncorhynchus tshawytscha) for chronic toxicity evaluation. Baser et al. (2003) investigated the acute toxicity of permethrin (a synthetic pyrethroid pesticide) on guppy fish (Poecilia reticulata). Pretti et al. (2006) assessed the acute toxicity of several ILs' towards zebrafish (daniorerio). Sarikaya et al. (2007) used guppy fish to estimate the toxicity of Fenitrothion (O,O-dimethyl-O-(3-methyl-4-nitrophenyl) phosphorothioate). Wang et al. (2010) estimated the toxicity of 1-methyl-3-octylimidazolium bromide
([C $\left.\left.\mathrm{C}_{8} \mathrm{mim}\right][\mathrm{Br}]\right)$ using goldfish (Carassius auratus). Dumitrescu et al. (2010) evaluated the acute toxicity of tetrabuthylammonium bromide using zebrafish. Li et al. (2013) employed goldfish toxicity to evaluate the toxicity of 1-methyl-3-octylimidazolium bromide $\left(\left[\mathrm{C}_{8} \mathrm{mim}\right][\mathrm{Br}]\right)$. Most researchers in recent years have carried acute toxicity tests for at least $48 \mathrm{~h}$ and usually $96 \mathrm{~h}$. For more information regarding toxicity assessment using guppy fish (Poecilia reticulata), readers can refer to PAN (Pesticide Action Network) Pesticides Database (http://www.pesticideinfo.org) and ECOTOX database (http://cfpub.epa.gov/ecotox/). The recent searching (in 2012) with "Guppy (Poecilia reticulata) toxicity studies" gave around 4104 individual studies on this species with different chemicals, which is even greater than with goldfish, Carassius auratus (3290). Other studies can be found with zebra fish, Danio rerio (4658), bluegill, Lepomis macrochirus (9677), rainbow trout, Oncorhynchus mykiss (26662) and fathead minnow, pimephales promelas (15128). For more detailed information on the acute toxicity tests of different fish species, readers are directed to the summary tables provided by the U.S. fish and wildlife service reports (Wood, 1953; Hollis and Lennon, 1954), the handbook of acute toxicity of chemicals to fish and aquatic invertebrates (Waynon and Finley, 1980) and work of Baser et al. (2003).

In this study, the acute fish toxicity study was conducted according to the prescribed guideline OECD 203 (Organisation for Economic Cooperation and Development) (OECD, 1992) using freshwater Guppy fish (Poecillia reticulata) to estimate the toxicity of two phosphonium ILs. To our knowledge there is no published literature regarding the toxicity $\left(\mathrm{LC}_{50}\right)$ of these ILs.

\section{MATERIALS AND METHODS}

\subsection{Chemicals}

Chemicals used in this study were obtained from commercial sources and had been used without drying and further purification. All ILs' were synthesized according to established methods (Bradaric et al., 2003; Cieniecka-Roslonkiewicz et al., 2005). An equivalent of tertiary phosphine was added dropwise to the appropriate alkylating reagent under nitrogen and stirred at a temperature rising from 30 to $200^{\circ} \mathrm{C}$. The reaction time normally varies from 10 to $29 \mathrm{~h}$. The speed of adding the 
tertiary phosphine to the alkylating reagent can be adjusted until no free tertiary phosphine can be formed in the reaction mixture. After the addition was complete, the mixture was stirred for 2 to $3 \mathrm{~h}$ at the highest temperature reached $\left(200^{\circ} \mathrm{C}\right)$.

For the synthesis of triphenyl- $n$-hexyl phosphonium halides, the general procedure started using a round bottom flask with side arm adaptor and septum, which was dried over high vacuum and purged three times with nitrogen. Then, it was charged with triphenyl phosphine (2 $\mathrm{mL}, 5.79 \mathrm{mmoL}$ ).

The flask was subsequently immersed into an oil bath $\left(50^{\circ} \mathrm{C}\right)$, the appropriate haloalkane was added via syringe and the mixture was stirred at $50^{\circ} \mathrm{C}$, before the product was dried at high vacuum overnight. The general structures of these ILs' are shown in Fig. 1.

\subsection{Fish Acute Toxicity Test}

The species used for this study is female guppy fish (Poecilia reticulata). The fish were purchased from a fish tackling shop in Perak, Malaysia and brought to the laboratory within $15 \mathrm{~min}$ of purchase in plastic bags containing sufficient amounts of water for sustainability. Upon arrival at the test site, the fish were placed in plastic tanks for acclimation. Prior to the toxicity test, the fish were held in the laboratory for 12 days. The fish were fed twice daily, once in the morning and once in the evening. The fish were kept under normal laboratory illumination with a daily photoperiod of $12-16 \mathrm{~h}$. The temperature of the water was between $23 \pm 2{ }^{\circ} \mathrm{C}$. The dissolved oxygen and $\mathrm{pH}$ of the water were 5-7 ppm and 7 respectively. The fish were observed carefully every day for signs of disease, stress, physical damage and mortality. Dead and abnormal specimens were removed immediately upon observation. After the adaptation period was complete; a group of 10 healthy fish were

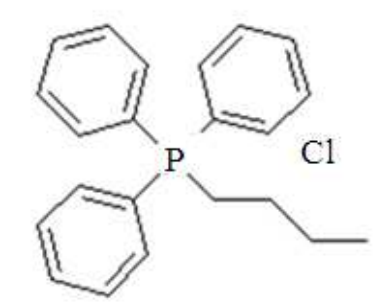

Butyltriphenylphosphonium chloride selected randomly and placed into $6.5 \mathrm{~L}$ plastic tanks provided with electric air pumps. Healthy fish can be recognized by their normal swimming style. Fish swimming abnormally should not be selected as they may have a weak resistance to the chemicals used in testing. Initially the experiments were conducted using tap water. Unfortunately, the results were rejected due to an abnormal death rate of the fish. Therefore, lake water was then used to avoid the chlorine contamination of tap water. Each tank was equipped with $5 \mathrm{~L}$ of lake water. No food was provided for the fish during the test. The weight of each fish is approximately $0.5 \mathrm{~g}$. The acute fish toxicity test was performed according to the OECD standard methods (OECD, 1992). Each IL was tested for four concentrations. Different concentrations were added to each testing tank. Behaviors of the fish were monitored closely and dead fish were removed immediately. The number of dead fish for each concentration was recorded after 24, 48, 72 and $96 \mathrm{~h}$. The median Lethal Concentration $\left(\mathrm{LC}_{50}\right)$ that is the ILs'concentration in water which kills $50 \%$ of the test batch of fish within a continuous period of exposure of 24, 48, 72 and $96 \mathrm{~h}$. were calculated. The results from the experiment were compared with acute toxicity rating scale provided by U.S. Fish and Wildlife Service (USFWS) (Table 1).

Table 1. Acute toxicity rating scale by Fish and Wildlife Service (FWS)

\begin{tabular}{ll}
\hline Relative toxicity & Aquatic $\mathrm{LC}_{50}(\mathrm{mg} / \mathrm{L})$ \\
\hline Super toxic & $0.01-0.1$ \\
Highly toxic & $0.1-1$ \\
Moderately toxic & $1-10$ \\
Slightly toxic & $10-100$ \\
Practically nontoxic & $100-1000$ \\
Relatively harmless & $>1000$ \\
\hline
\end{tabular}

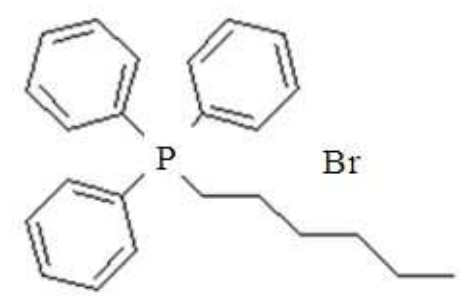

Butyltriphenylphosphonium bromid

Fig. 1. Structures of ILs used in this study 


\section{RESULTS AND DISCUSSION}

The screening tests for the two ILs were conducted with the concentration of $100 \mathrm{mg} \mathrm{L}^{-1}$ as limit test, which showed the range of toxicity below $100 \mathrm{mg} \mathrm{L}^{-1}$ and it lies between 50 to $100 \mathrm{mg} \mathrm{L}^{-1}$. The observations of the fish mortality for butyl triphenyl phosphonium chloride and hexyl triphenyl phosphonium bromide are presented in Table 2 and 3.

It can be clearly seen that at higher concentrations, the number of dead fish increased. Numbers of dead fish in the time period prescribed by the test were used to determine the mortality percent and lethal concentration $\left(\mathrm{LC}_{50}\right)$. The cumulative percentage mortality for $96 \mathrm{hr}$ exposure time is plotted against a logarithm concentration (Fig. 2 and 3 ).

Data presented in Table 4 and 5 were used to determine $\mathrm{LC}_{50}$ values employing probit analysis
(Finney, 1978). The best fit dose-response linesfor butyl triphenylphosphonium chloride and hexyl triphenylphosphonium bromide were plotted in Fig. 4 and 5 respectively. Transformation of the toxicity curve to a straight line indicates that the lethal threshold concentration is estimated correctly. The fact was confirmed by Burdick (1957). Probit equations were derived from the experimental data presented in Table 4 and 5 for both ILs'; which are $\mathrm{Y}=9.95 \times 13.56$ and $\mathrm{Y}=3.63 \times-1.49$ respectively. The correlation coefficients, $\mathrm{R}^{2}$ were obtained 94 and $99 \%$ respectively. This is confirming the accuracy of the results obtained from the experiment. Probit equations obtained from this work can be used to examine the toxicity of any ILs' from the same family without the need for experimental work. It should be noted that these two equations are only valid to estimate the $\mathrm{LC}_{50}$ for the same aquatic organism (Guppy fish).

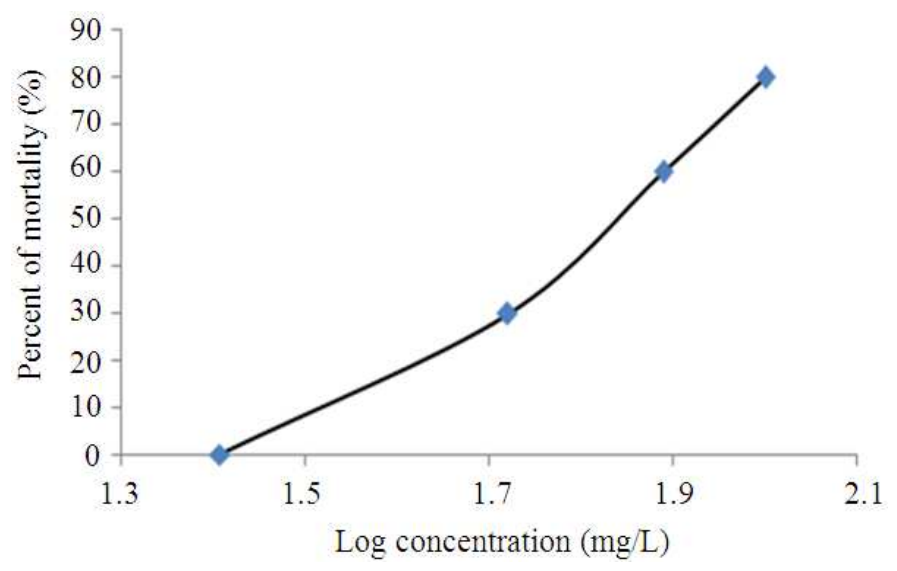

Fig. 2. $\log _{10}$ concentration Vs. percent of mortality for butyl triphenyl phosphonium chloride

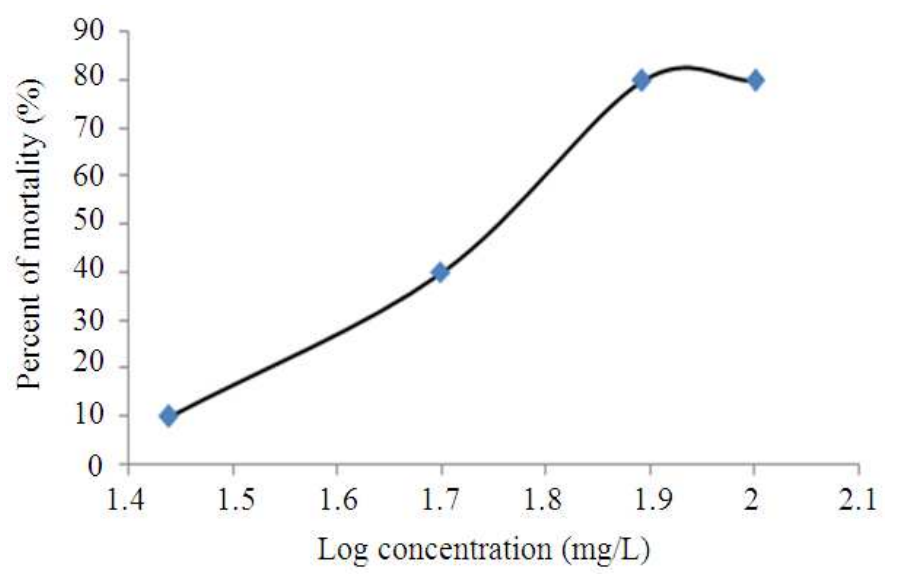

Fig. 3. $\log _{10}$ concentration Vs. percent of mortality for hexyl triphenyl phosphonium bromide 
Mohanad El-Harbawi et al. / American Journal of Environmental Science 9 (6): 511-517, 2013

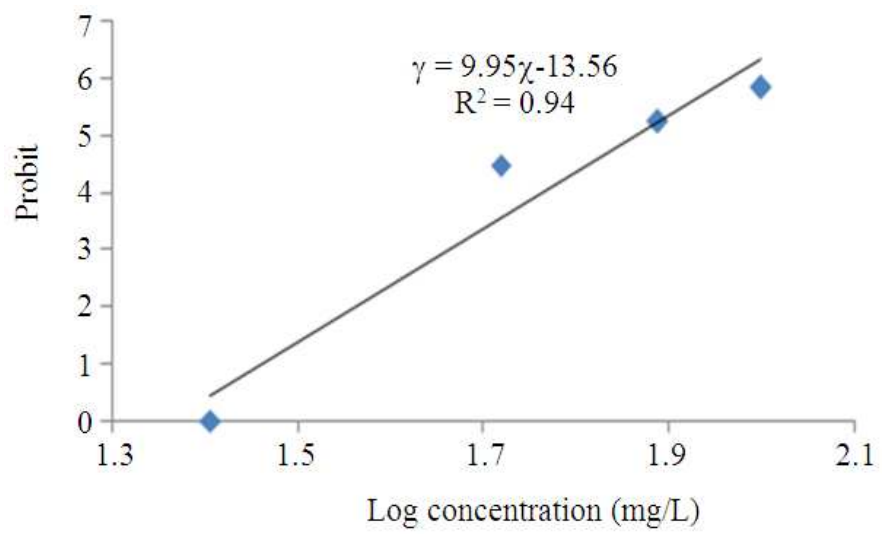

Fig. 4. $\log _{10}$ concentration Vs. probit for butyl triphenyl phosphonium chloride

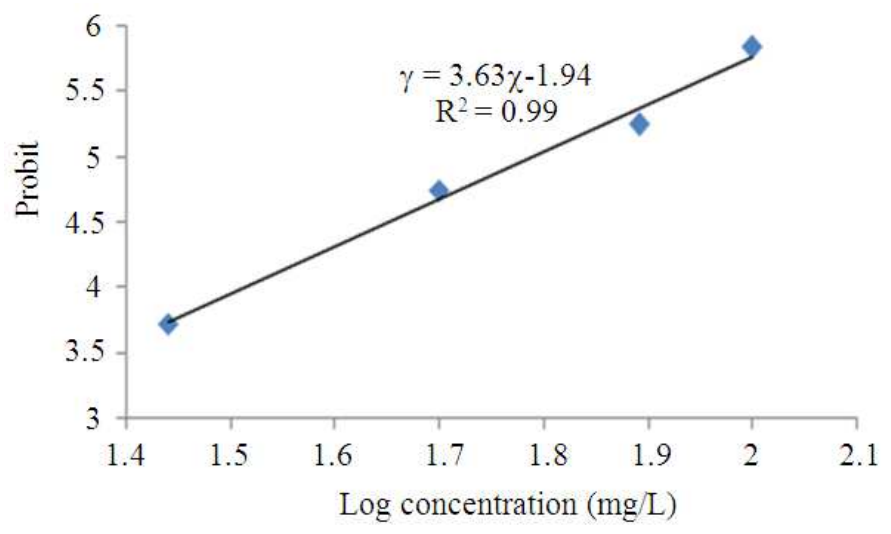

Fig. 5. $\log _{10}$ concentration Vs. probit for hexyl triphenyl phosphonium bromide

Table 2. Mortalities of acute toxicity test for butyl triphenyl phosphonium chloride

\begin{tabular}{llllll}
\hline Concentration $(\mathrm{mg} / \mathrm{L})$ & $24 \mathrm{~h}$ & $48 \mathrm{~h}$ & $72 \mathrm{~h}$ & $96 \mathrm{~h}$ & Total fish died \\
\hline 25.5 & 0 & 0 & 0 & 0 & 0 \\
52.5 & 0 & 1 & 1 & 1 & 3 \\
77.5 & 0 & 2 & 2 & 2 & 6 \\
100 & 1 & 2 & 2 & 3 & 8 \\
\hline
\end{tabular}

Table 3. Mortalities of acute toxicity test for hexyl triphenyl phosphonium bromide

\begin{tabular}{llllll}
\hline Concentration $(\mathrm{mg} / \mathrm{L})$ & $24 \mathrm{~h}$ & $48 \mathrm{~h}$ & $72 \mathrm{~h}$ & $96 \mathrm{~h}$ & Total fish died \\
\hline 27.5 & 0 & 0 & 0 & 1 & 1 \\
50.0 & 1 & 1 & 2 & 2 & 4 \\
78.0 & 2 & 2 & 2 & 2 & 8 \\
100 & 2 & 2 & 2 & 2 & 8 \\
\hline
\end{tabular}

Table 4. Log dose and percentage of mortality for butyl triphenyl phosphonium chloride

\begin{tabular}{llllll}
\hline Dose $(\mathrm{mg} / \mathrm{L})$ & Log dose $(\mathrm{mg} / \mathrm{L})$ & Total fish & Total mortality & \% of mortality & Probit variable \\
\hline 25.5 & 1.407 & 10 & 0 & 0 & 0.00 \\
52.5 & 1.720 & 10 & 3 & 30 & 4.48 \\
77.5 & 1.889 & 10 & 6 & 60 & 5.25 \\
100 & 2.000 & 10 & 8 & 80 & 5.84 \\
\hline
\end{tabular}


Mohanad El-Harbawi et al. / American Journal of Environmental Science 9 (6): 511-517, 2013

Table 5. Log dose and percentage of mortality for hexyl triphenyl phosphonium bromide

\begin{tabular}{llllll}
\hline Dose $(\mathrm{mg} / \mathrm{L})$ & Log dose $(\mathrm{mg} / \mathrm{L})$ & Total Fish & Total mortality & \% of mortality & Probits variable \\
\hline 27.5 & 1.439 & 10 & 1 & 10 & 3.72 \\
50.0 & 1.699 & 10 & 4 & 40 & 4.75 \\
78.0 & 1.892 & 10 & 8 & 80 & 5.25 \\
100 & 2.000 & 10 & 8 & 80 & 5.84 \\
\hline
\end{tabular}

$\mathrm{LC}_{50}$ values have been obtained from Fig. 2 and 3 or from Fig. 4 and 5 to be $67.5 \mathrm{mg} \mathrm{L}^{-1}$ for butyl triphenylphosphonium chloride and $56.3 \mathrm{mg} \mathrm{L}^{-1}$ for hexyl triphenylphosphonium bromide.

According to the acute toxicity rating scale provided by the U.S. Fish and Wildlife Service (USFWS), these values lie within the range of slightly toxic.

\section{CONCLUSION}

Acute toxicity method was used to evaluate the $\mathrm{LC}_{50}$ of twophosphonium based ionic liquids. The acute fish toxicity test was performed using Guppy fish (Poecilia reticulata) according to the OECD 203 standard methods. Results obtained from this work indicated that the butyl triphenyl phosphonium chloride and hexyl triphenyl phosphonium bromide are slightly toxic. The result from this study can be beneficial to industrial people who use phosphonium based ionic liquids in their industrial processes.

\section{ACKNOWLEDGMENT}

The researchers acknowledge the Petronas Ionic Liquid Center (PILC) and Chemical Engineering Department, Universiti Teknologi PETRONAS for their support in conducting this study. Mohanad El-Harbawi extends the appreciation to the Deanship of Scientific Research at King Saud University for funding this study through research group no RGP-VPP-303.

\section{REFERENCES}

Ardali, Y., 1990. Heavy Metal Expurgation from IIndustrial Waters by Absorption. MS Thesis, Universitesi Fen Bilimleri Ens, Samsun, Turkish.

Baser, S., F. Erkoc, M. Selvi and O. Kocak, 2003. Investigation of acute toxicity of permethrin on guppies Poecilia reticulata. Chemosphere, 51: 469474. PMID: 12615098

Bernot, R.J., E.E. Kennedy and G.A. Lamberti, 2005a. Effects of ionic liquids on the survival, movement and feeding behavior of the freshwater snail, Physa acuta. Environ. Toxicol. Chem., 24: 1759-1765. DOI: 10.1897/04-614R.1
Bernot, R.J., M.A. Brueseke, M.A. Evans-White and G.A. Lamberti, 2005b. Acute and chronic toxicity of imidazolium-based ionic liquids on Daphnia magna. Environ. Toxicol. Chem., 24: 87-92. PMID: 15683171

Bradaric, C.J., A. Downard, C. Kennedy, A.J. Robertson and Y. Zhou, 2003. Industrial preparation of phosphonium ionic liquids. Green Chem., 5: 143152. DOI: 10.1039/B209734F

Burdick, G.E., 1957. Graphical method for deriving threshold values of toxicity and the equation of the toxicity curve. N.Y. Fish Game J.

Cieniecka-Roslonkiewicz, A., J. Pernak, J. Kubis-Feder, A. Ramani and A.J. Robertson et al., 2005. Synthesis, anti-microbial activities and antielectrostatic properties of phosphonium-based ionic liquids. Green Chem., 7: 855-862. DOI: 10.1039/b508499g

Dube, P.N., B.B. Hosetti, 2010. Behaviour surveillance and oxygen consumption in the freshwater fish Labeo rohita (Hamilton) exposed to sodium cyanide. Biotechnol. Anim. Husbandry, 26: 91-103. DOI: 10.2298/BAH1002091D

Dumitrescu, G., L. Petculescu-Ciochina, I. Bencsik, D. Dronca and L. Boca, 2010. Evaluation on acute toxicity of tetrabuthylammonium bromide ionic liquid at histological structure of some organs in zebrafish (Danio rerio). Aquaculture, Aquarium, Conservation Legislation, 3: 404-414.

Finney, D.J., 1978. Statistical Method in Biological Assay. 3rd Edn., Oxford Univ Pr., ISBN-10: 0028446402, pp: 508.

Flieger, J., 2011. Ionic Liquids: Applications and Perspectives. InTech-Open Access Company.

Freire, M.G., P.J. Carvalho, I.M. Marrucho, J.A.P. Coutinho and A.M. Fernandes, 2006. Phosphonium based ionic liquids and water: Mutual solubilities. Sixteenth Symposium on Thermophysical Properties. Boulder, CO, USA.

Hollis, E.H. and R.E. Lennon, 1954. The toxicity of 1085 chemicals to fish (part 2). The U.S. fisher and wildlife service report. 
Latala, A., P. Stepnowski, M. Nedzi and W. Mrozic, 2005. Marine toxicity assessment of imidazolium ionic liquids: Acute effects on the Baltic algae Oocystis submarina and Cyclotella meneghiniana. Aquat. Toxicol., 73: 91-98. DOI: 10.1016/j.aquatox.2005.03.008

Li, X.Y., S.H. Zeng, W.H. Zhang, L. Li and M. Shuai et al., 2013. Acute toxicity and superficial damage to goldfish from the ionic liquid 1-methyl-3octylimidazolium bromide. Environ. Toxicol., 28: 207-214. DOI: $10.1002 /$ tox.20712

Madria, N., T.A. Arunkumar, N.G. Nair, A. Vadapalli and Y.W. Huang et al., 2013. Ionic liquid electrolytes for lithium batteries: Synthesis, electrochemical and cytotoxicity studies. J. Power Sources, 234: 277-284. DOI: 10.1016/j.jpowsour.2013.02.002

McKim, J.M., 1977. Evaluation of tests with early life stages of fish for predicting long term toxicity. J. Fisheries Res. Board Canada, 34: 1148-1154. DOI: 10.1139/f77-172

OECD, 1992. Fish acute toxicity test In OECD Guidelines Fortesting Chemicals. Organisation for Economic Cooperation and Development.

Peric, B., Marti, E., Sierra, J., Cruanas, R. and Garau, A., 2012. Recent Advances in Pharmaceutical Sciences. In: Transworld Research Network, Muñoz-Torrero, D., D. Haro and J. Vallès, (Eds.).

Pernak, J., F. Stefaniak and J. Weglewski, 2005. Phosphonium acesulfamate based ionic liquids. Eur. J. Org. Chem., 2005: 650-652. DOI: 10.1002/ejoc. 200400658
Pretti, C., C. Chiappe, D. Pieraccini, M. Gregori and F. Abramo et al., 2006. Acute toxicity of ionc liquids to the zebrafish (Dania rerio). Green Chem., 8: 238-240.

Rand, G.M. and P.G. Wells, 1995. Introduction of aquatic toxicology. Taylor and Francis, Washington D.C.

Sarikaya, R., M. Selvi, O. Kocak and F. Erkoc, 2007. nvestigation of acute toxicity of fenitrothion on guppies Poecilia reticulata. J. Applied Toxicol., 27: 318-321. DOI: 10.1002/jat.1193

Walden, P., 1914. Molecular weights and electrical conductivity of several fused salts. Bull. Acad. Sci. St. Petersbourg.

Wang, S.H., P.P. Huang, X.Y. Li, C.Y. Wang and W.H. Zhang et al., 2010. Embryonic and developmental toxicity of the ionic liquid 1-methyl-3octylimidazolium bromide on goldfish. Environ. Toxicol., 25: 243-250. DOI: 10.1002/tox.20496

Waynon, W.J. and M.F. Finley, 1980. Handbook of acute toxicity of chemicals to fish and aquatic invertebrates. United States Department of the Interior Fish and Wildlife Service, Resources Publication 137.

Wilkes, J.S., J.A. Levisky, R.A. Wilson and C.L. Hussey, 1982. Dialkylimidazolium chloroaluminate melts: A new class of room-temperature ionic liquids for electrochemistry, spectroscopy and synthesis. Inorg. Chem., 21: 1263-1264. DOI: 10.1021/ic00133a078

Wood, E.M., 1953. The toxicity of 3400 chemicals to fish (part 1). The U.S. Fisher and Wildlife Service Report. 